\title{
Yolk sac and its effects on fetal prognosis
}

\author{
Sankar Kumar Das ${ }^{1,2 *}$, Priyanka Roy ${ }^{1,3}$
}

\begin{abstract}
${ }^{1}$ Department of Obstetrics and Gynecology, Swagat Hospital and Research Center, Bongaigaon, Assam, India ${ }^{2}$ Department of Obstetrics and Gynecology, Gauhati Medical College and Hospital, Guwahati, Assam, India ${ }^{3}$ Department of Obstetrics and Gynecology, Assam Medical College and Hospital, Dibrugarh, Assam, India
\end{abstract}

Received: 13 August 2018

Revised: 24 October 2018

Accepted: 27 October 2018

*Correspondence:

Dr. Sankar Kumar Das,

E-mail: drsankarkumardas@rediffmail.com

Copyright: ( ) the author(s), publisher and licensee Medip Academy. This is an open-access article distributed under the terms of the Creative Commons Attribution Non-Commercial License, which permits unrestricted non-commercial use, distribution, and reproduction in any medium, provided the original work is properly cited.

\begin{abstract}
Background: The yolk sac is the first extra embryonic structure that becomes sonographically visible within the gestational sac. It provides nutritional, metabolic, endocrine, immunologic, and hematopoietic functions during organogenesis in embryonic life, before placental circulation is established. Spontaneous abortion rates are significantly elevated where the yolk sac volume falls outside the $5^{\text {th }}$ to $95^{\text {th }}$ percentile. Abnormal morphological appearance of the yolk sac is also suggestive of serious growth disorders of the fetus. The aim is to find out the predictive value of yolk sac on outcome of the pregnancy and any probable relationship of the yolk sac pattern with the gender of the fetus.

Methods: The present study was carried out on fifty patients in their first trimester of pregnancy. Patients were divided into their respective gestational age groups and according to the morphology of the yolk sac. Data were compared using Chi square test. p value less than 0.5 was considered significant.

Results: Out of the fifty patients, twenty-nine were having regular yolk sac, eleven were with irregular yolk sac and ten were with hyperechoic yolk sac. There was a significant number of fetal demise in the cases with hyperechoic and irregular yolk sac. Also, there were hardly any live births in the few cases in which the yolk sac was either too small or too big.

Conclusions: The present study concludes that along with a yolk sac of a given normal range for its size, it should also be of normal morphology for better prognosis of the pregnancy. Also, the increase in the number of female live births needs further studies as to whether there is any abnormality in the $\mathrm{Y}$ chromosome causing morphologically abnormal yolk sac and subsequent fetal demise.
\end{abstract}

Keywords: First trimester, Pregnancy outcome, Transvaginal sonography, Yolk sac, Yolk sac morphology, Yolk sac size

\section{INTRODUCTION}

The yolk sac is the first extra embryonic structure that becomes sonographically visible within the gestational sac and acts as the primary route of exchange between the human embryo and the mother before the placental circulation is established. It provides nutritional, metabolic, endocrine, immunologic, and hematopoietic functions during organogenesis in embryonic life, and is considered to reach its highest level of functional activity between the $4^{\text {th }}$ and $7^{\text {th }}$ week of embryonic development. ${ }^{1}$

It is a critical landmark that identifies a true gestational sac. ${ }^{2}$ In fact it is the first conceptional structure that is usually visualized by TVS when a gestational sac measures over $8 \mathrm{~mm} .^{3}$ In a normal pregnancy it should be 
possible to observe the yolk sac between 5 to 12 weeks of pregnancy.

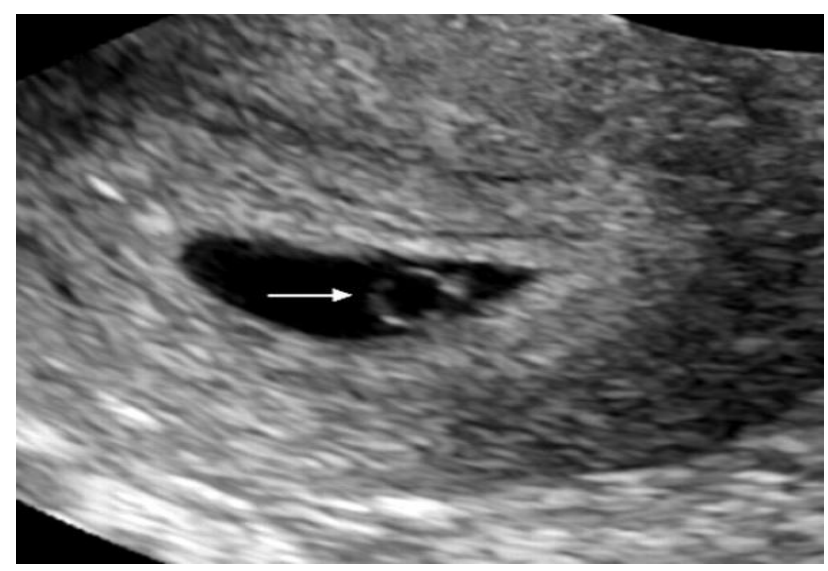

Figure 1: Gestational yolk sac at 5 weeks shown by arrow, no embryo is visible in this scan.

Sonography shows the yolk sac as a round structure that is made up of an anechoic center bordered by a regular well-defined echogenic rim. The diameter of yolk sac is usually $3-4 \mathrm{~mm}$ and increases in size upto $10^{\text {th }}-11^{\text {th }}$ week of gestation, afterward it gradually decreases. ${ }^{3}$ Spontaneous abortion rates are significantly elevated where the yolk sac volume falls outside the $5^{\text {th }}$ to $95^{\text {th }}$ percentile. Abnormal morphological appearance of the yolk sac or size more than $9 \mathrm{~mm}$ are suggestive of serious growth disorders of the fetus. Pregnancies that have mean yolk sac diameter equal or larger than $5 \mathrm{~mm}$ on first trimester ultrasound are also associated with a threefold increased risk for 1 st trimester loss independent of maternal risk factors like age, body mass index, polycystic ovarian syndrome, smoking, diabetes. ${ }^{4}$ Yolk sacs with mainly wrinkled margins, indented walls, or both are usually identified as having an irregular shape. ${ }^{5}$

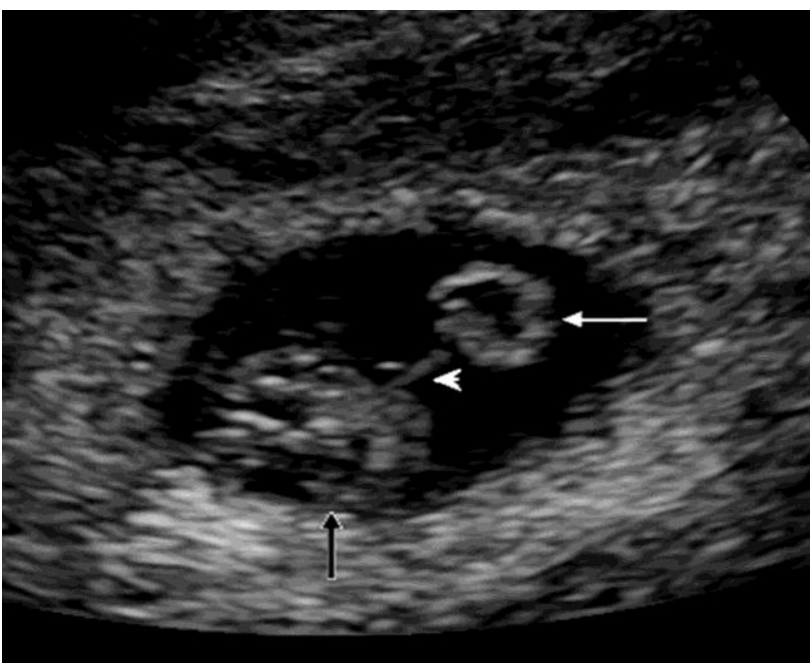

Figure 2: Irregular yolk sac; transvaginal sonography at 7 weeks 1 day shows a live embryo (black arrow) and an irregular yolk sac (white arrow); the vitelline duct (arrowhead) is also shown.
There are a number of clinical studies that have declared that the persistence of an irregular yolk sac shape may be used to indicate an adverse gestational outcome. ${ }^{6,7}$ Just the same, a newly published study suggests that an irregular yolk sac shape is unrelated to an increased risk of spontaneous abortion. ${ }^{5}$ A calcified yolk sac may appear as an echogenic ring on sonography. ${ }^{8}$ It has not been reported to be associated with a live embryo before the $12^{\text {th }}$ week of gestation. A calcified yolk sac would be observed only with a dead embryo because the yolk sac would undergo calcification within a few days after embryonic death has occurred. ${ }^{9}$ An echogenic (rather than anechoic) yolk sac is different from a calcified yolk sac in that echogenicity may represent various types of materials other than calcium. To our knowledge, only 1 study reported that an echogenic yolk sac can be associated with fetal death or abnormalities. ${ }^{10}$ In the related literature, it has also been anecdotally emphasized that an echogenic yolk sac does not predict an embryonic anomaly or death. ${ }^{8}$ In fact, large-scale prospective studies are anticipated to clarify the prognostic importance of echogenic yolk sac. ${ }^{11}$

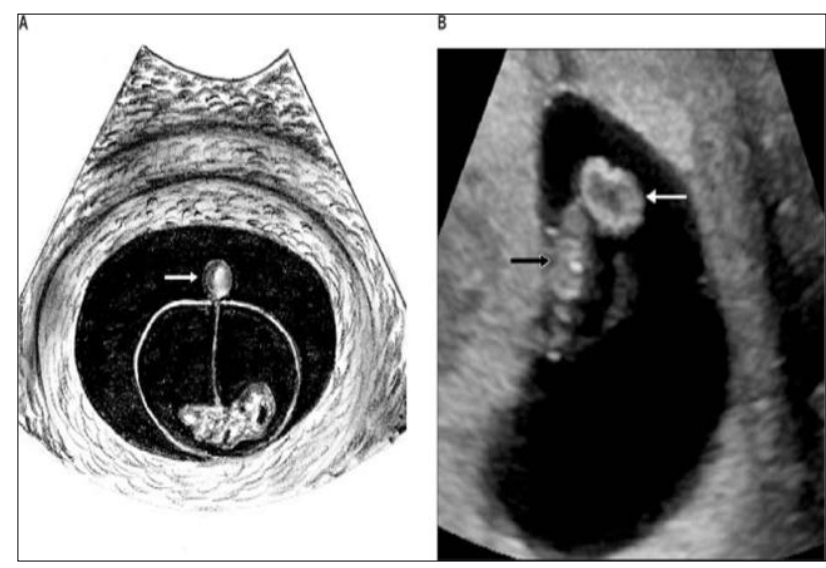

Figure 3: Echogenic yolk sac; A: diagram shows an echogenic yolk sac (arrow) within the gestational sac; B: transvaginal sonography at 6 weeks 6 days shows a live embryo (black arrow) and an echogenic yolk sac (white arrow).

\section{METHODS}

The present study was carried out on 50 patients in the Department of Obstetrics and Gynaecology at Swagat Hospital and Research Center, Bongaigaon, Assam. All pregnant women in their first trimester of pregnancy were recruited for the study on the basis of inclusion/ exclusion criteria. Detailed history was taken to rule out medical and surgical illnesses which could affect our study. Thorough general and physical examination was done.

\section{Inclusion criteria}

- Uncomplicated, singleton pregnancy belonging to gestational age between 5-11 weeks were included for the study. 


\section{Exclusion criteria}

- Women with structural anomalies of uterus and cervix, known medical disorders causing abnormal pregnancy outcome i.e. patients with anemia, hyperthyroidism, diabetes mellitus, chronic hypertension, molar pregnancy and patients refusing for transvaginal sonography, who were unwilling for follow up were excluded.

Written informed consent was taken from the patients. Two-dimensional transvaginal sonography was performed on the patients as routine procedure during their first trimester and the size and shape of the yolk sac, echogenicity of the sac at the rim and center of yolk sac, any degenerative changes such as calcification were noted.

Yolk sac that had the following characteristic were classified as normal: diameter $2-5 \mathrm{~mm}$, round shape, absence of degenerative changes, equal with no. of embryos, presence of echogenic rim and hypoechoic center. Yolk sac that had diameters smaller than $2 \mathrm{~mm}$ or larger than $5 \mathrm{~mm}$, were not round, had evidence of degenerative changes, hyperechoic center, and unequal number with embryos were considered abnormal.

Based on the above criteria patients were divided into their respective gestational age groups and morphology of the yolk sac. All cases were followed until delivery. Data were compared using Chi square test, $\mathrm{p}$ value less than 0.5 was considered significant.

\section{RESULTS}

Out of the fifty patients, twenty-nine were having regular yolk sac, eleven were with irregular or beaded yolk sac and ten were with hyperechoic yolk sac. The number of abortions were quite high in the group with hyperechoic yok sac, followed by that group with irregular or beaded yolk sac. p value was 0.00008 which was significant (less than 0.5 ).

The patients were divided according to their gestational weeks and corresponding mean yolk sac diameter was observed for the respective groups. The no of live births and abortions in each group was observed. $\mathrm{p}$ value was found to be 0.63 which was not significant.

Table 1: Pregnancy outcome in relation with yolk sac morphology.

\begin{tabular}{|lllll|}
\hline & Regular & Irregular & Hyperechoic & p value \\
\hline Live births & 24 & 4 & 1 & 0.00008 \\
\hline Abortions & 5 & 7 & 9 & 0.00 \\
\hline Total & 29 & 11 & 10 & \\
\hline
\end{tabular}

Table 2: Pregnancy outcome in relation with gestational weeks and corresponding yolk sac size.

\begin{tabular}{|lllllll|}
\hline Gest age in weeks & $5-5.9$ & $6-6.9$ & $7-7.9$ & $8-8.9$ & $9-9.9$ & $10-10.9$ \\
\hline Yolk sac size in mm (mean \pm SD) & $3.61 \pm 1.98$ & $4.41 \pm 1.03$ & $4.07 \pm 1.05$ & $4.61 \pm 1.22$ & $4.84 \pm 0.99$ & $6.50 \pm 1.22$ \\
\hline Live births & 3 & 10 & 4 & 6 & 4 & 2 \\
\hline Abortions & 6 & 4 & 3 & 4 & 3 & 1 \\
\hline
\end{tabular}

Table 3: Gender variation in the live births.

\begin{tabular}{|lll|}
\hline & Male & Female \\
\hline Live birth & 11 & 17 \\
\hline
\end{tabular}

Twenty-one (42\%) out of the fifty cases had abortion. Five $(23 \%)$ of them had regular yolk sac, seven $(33 \%)$ had irregular yolk sac and nine $(42 \%)$ of them had hyperechoic yolk sac. Two cases had yolk sac of size less than $2 \mathrm{~mm}$ with regular morphology that got aborted out of these cases. Three cases among them had yolk sac size of more than $6 \mathrm{~mm}$ out of which one with size of $7 \mathrm{~mm}$ with regular shape got aborted while one with size $8 \mathrm{~mm}$ with irregular shape got aborted. It was observed that sex of most of the live birth babies having small yolk sac size that survived till term were females.

\section{DISCUSSION}

In the present study yolk sac was seen in all the cases selected for study. Twenty one of the fifty cases got aborted out of which two cases (4\% of total cases) had yolk sac size of less than $2 \mathrm{~mm}$. In the study done by Adila $\mathrm{P}$ et al a small sac was related to around $40 \%$ of abortion. ${ }^{12}$ In the present study three cases were detected with large yolk sac of more than $6 \mathrm{~mm}$, two of them got aborted. One was having a regular morphology with $7 \mathrm{~mm}$ size at 10 weeks gestation while another one was with irregular morphology of $8 \mathrm{~mm}$ size at 5 weeks gestation. Another yolk sac of $7 \mathrm{~mm}$ at 10 weeks gestation with regular morphology however survived till term. An abnormally large yolk sac indicates poor obstetric outcome. 
Berdahl et al has shown that a yolk sac diameter of greater than $5 \mathrm{~mm}$ is associated with an increased risk of spontaneous abortion. ${ }^{13}$ However, few authors have suggested presence of a large yolk sac (of more than 8 $\mathrm{mm}$ ) in a normal live pregnancy. ${ }^{14}$

In the present study, of the five cases with regular morphology that got aborted one had size more than $6 \mathrm{~mm}$, two cases had size less than $2 \mathrm{~mm}$, however two cases of these five cases with regular morphology, although had a yolk sac size of $2-6 \mathrm{~mm}$, seemed inefficient for the required gestational age; one at 8 weeks 2 days had a yolk sac of $3.2 \mathrm{~mm}$ while another at 7 weeks 4days had a size of $2.8 \mathrm{~mm}$. There's a probability that a yolk sac, that even if it falls within the normal range, but if its small for the given gestational age, can cause abortion due to its inefficiency to supply the required nutrients to sustain the fetus at that given, or growing, gestational age.

In the present study there was a significant number of abortions with abnormality in the morphology of yolk sac. Abnormal yolk sac shape is associated with abnormal pregnancy outcome with a sensitivity of $29 \%$, specificity of $95 \%$, positive predictive value of $47 \%$ and negative predictive value of $90.5 \% .^{3}$ In the study done by Moradan S et al fifty percent of the cases with distorted yolk sac had spontaneous abortion. In that same study one of the four cases with hyperechoic yolk sac had spontaneous abortion. ${ }^{15}$ In the present study however a significant no of cases with hyperechoic yolk sac had abortion. Cho FN et al and Szabo J et al in their studies reported that an echogenic yolk sac can be associated with fetal death or abnormalities. ${ }^{14}$ However, Levi and Lyon declared that an echogenic yolk sac is not always associated with abnormality or impending fetal demise and may revert to a normal appearance within one week. ${ }^{16}$ Persistent hyperechoic yolk sac could be a cause of fetal demise as seen in the present study. In the present study seven number of cases with irregular or beaded yolk sac had abortion. Tan $\mathrm{S}$ et al in their study suggested that irregular yolk sac is not associated with increased risk of spontaneous abortion. ${ }^{17}$

There was a gender variance seen in the present study related to the gender of the babies. Majority of the live borns having a small yolk sac were female. Further studies are required in this matter to conclude whether there could be any chromosomal defect of the $\mathrm{Y}$ chromosome in causing an increase in the rate of spontaneous abortion in male fetuses having a abnormal yolk sac.

\section{CONCLUSION}

It was observed in the study that there was a definite effect of the abnormal morphology of the yolk sac on the fetal prognosis. There was a significant number of fetal demise in the cases with hyperechoic and irregular yolk sac. Although most of the cases in the present study had yolk sac that fall in the normal range of $2-5 \mathrm{~mm}$, but in the few cases that had a yolk sac of size either more or less than the given range, there were hardly any live births. The yolk sac with a regular morphology but with a small size or big size resulted in fetal demise in the given study. Thus, the present study concludes that along with a yolk sac of a given normal range, it should also be of normal morphology for better prognosis of the pregnancy. Also, the increase in the number of female live births needs further studies as to whether there is any abnormality in the $\mathrm{Y}$ chromosome causing morphologically abnormal yolk sac and subsequent fetal demise.

\section{Funding: No funding sources}

Conflict of interest: None declared

Ethical approval: The study was approved by the Institutional Ethics Committee

\section{REFERENCES}

1. Pereda J, Niimi G. Embryonic erythropoiesis in human yolk sac: two different compartments for two different processes. Microsc Res Tech. 2008;71:85662.

2. Kurtz AB, Needleman L, Pennell RG, Baltarowich O, Vilaro M, Goldberg BB. Can detection of the yolk sac in the first trimester be used to predict the outcome of pregnancy? A prospective sonographic study. AJR Am J Roentgenol. 1992;158:843-7.

3. Kucuk T, Duru NK, Yenen MC, Dede M, Ergun A, Baser I. Yolk sac size and shape as predictors of poor pregnancy outcome. J Peronat Med. 1999;27:316-20.

4. Moradan S, Forouzeshfar M. Are abnormal yolk sac characteristics important factors in abortion rates? Int J Fertil Steril.2012;6(2):127-30.

5. Tan S, Ipek A, Pektas MK, Arifoğlu M, Teber MA, Karaoğlanoğlu M. Irregular yolk sac shape: is it really associated with an increased risk of spontaneous abortion? J Ultrasound Med. 2011;30:31-6.

6. Lindsay DJ, Lovett IS, Lyons EA. Yolk sac diameter and shape at endovaginal US: predictors of pregnancy outcome in the first trimester. Radiol. 1992;183:115-8.

7. Chao S, McGahan JP. Yolk sac. In: Goldberg BB, McGahan JP, eds. Atlas of Ultrasound Measurements. $1^{\text {st }}$ ed. Philadelphia, PA: CV Mosby Co; 2006:15-17.

8. Lyons EA, Levi CS. The first trimester. In: Rumack CM, Wilson SR, Charboneau JW, eds. Diagnostic Ultrasound. $3^{\text {rd }}$ ed. St Louis, MO: CV Mosby Co; 2005:1070-1100.

9. Harris RD, Vincent LM, Askin FB. Yolk sac calcification: a sonographic finding associated with intrauterine embryonic demise in the first trimester. Radiol. 1988;166:109-10.

10. Szabo J, Gellén J, Szemere G, Faragó M. Significance of hyper-echogenic yolk sac in firsttrimester screening for chromosome aneuploidy [in Hungarian]. Orv Hetil. 1996;137:2313-5. 
11. Tan S, Pektas MK, Arslan H. Sonographic evaluation of the yolk sac. J Ultrasound Med, AIUM. 2012;31(1):87-95.

12. Adija P, Selvi C, Rai L, Hebbar S. Evaluation of yolk sac diameter and embryonic heart rate as prognostic factors of gestational outcome in early singleton pregnancies. Scholars J App Med Sci (SJAMS). 2015;3(2A):543-50.

13. Berdahl DM, Blaine J, Van Voorhis B, Dokras A. Detection of enlarged yolk sac on early ultrasound is associated with adverse pregnancy outcomes. Fertil Steril. 2010;94:1535-7.

14. Cho FN, Chen SN, Tai MH, Yang TL. The quality and size of yolk sac in early pregnancy loss. Aust N Z J Obstet Gynaecol. 2006;46:413-8.
15. Moradan S, Forouzeshfar MF. Are abnormal yolk sac characteristics important factors in abortion rates?. Int J Fertil Steril. 2012;6(2):127-30.

16. Levi CS, Lyons EA, Lindsay DJ. Early diagnosis of nonviable pregnancy with endovaginal US. Radiol. 1988;167:383-5.

17. Tan S, Tangal NG, Kanat-Pektas M, Özcan AŞ, Keskin HL, Akgündüz G, et al. Abnormal sonographic appearances of the yolk sac: which can be associated with adverse perinatal outcome?. Med Ultrason. 2014;16(1):15-20.

Cite this article as: Das SK, Roy P. Yolk sac and its effects on fetal prognosis. Int J Reprod Contracept Obstet Gynecol 2018;7:4895-9. 